\title{
Principals' Roles and Responsibilities in Creating Inclusive School Environments for People with Disabilities
}

\author{
CHRISTINE ROUGOOR \\ Brock University
}

\begin{abstract}
Ontario education providers have a responsibility to accommodate the needs of their students and employees with disabilities (Ontario Human Rights Commission, 2008). Under the 2001 Ontarians with Disabilities Act, the Ministry of Education along with school boards are required to prepare, update, and make public accessibility plans that address the identification, removal, and prevention of barriers for people with disabilities (Valeo, 2010). However, in 2012, physical, architectural, and attitudinal impediments frequently fail to meet basic accessibility and equity standards. The purpose of this paper is to juxtapose my own personal narrative as a disabled teacher candidate, with literature about the roles and responsibilities of principals and administrators in creating inclusive school environments for people with disabilities. Administrators' roles in leadership, mediation, and collaboration, crucially influence the success of inclusive school organizations (Goddard \& Hart, 2007; Irvine et al., 2010; Ross \& Berger, 2009; Valeo, 2010), and directly affect the experiences of individuals therein. This paper highlights the need for principals to be knowledgeable about disability issues such as recognizing barriers, using preventative instead of reactive strategies toward physical disability concerns, and addressing challenges administrators face when trying to create integrative, inclusive school environments.
\end{abstract}

\section{Introduction}

In Canada, approximately one in seven people has a disability, equating to 4.4 million children and adults (Statistics Canada, 2009). For the sake of this paper, the term "disability" covers a broad range and degree of conditions, including physical, mental, and learning deficits; mental disorders; hearing or vision impairment; epilepsy; drug and/or alcohol dependencies; and environmental sensitivities (Ontario Human Rights Commission, 2008). A disability may be present from birth, caused by an accident, or developed over time (Statistics Canada, 2009). Regardless of when a disability is acquired, Ontario education providers have a responsibility to accommodate the needs of their students and employees with disabilities (Ontario Human Rights Commission, 2008). "School boards are required to embed the principles of equity and inclusive 
education in all aspects of their operations, including policy development, programming, and practices related to research, curriculum resources, instruction, and assessment" (Ontario Ministry of Education, 2011, p. 16).

I am a disabled teacher candidate. I rely fully on a manual wheelchair for mobility, and my stamina is lower than the average person my age. Two years before my first teaching practicum, I endured a catastrophic accident that paralyzed me from the chest down. In addition to mobility issues, I also have a mild speech impairment. I cannot speak loudly for long durations, and I experience "dry mouth" very quickly as a side effect of the medications I take. Overall, my physical challenges pose great difficulties, not only for me but also for the classes I teach, and the schools in which I work. The purpose of this paper is to juxtapose my own personal narrative as a disabled teacher candidate, with current literature about the roles and responsibilities of principals and administrators in creating inclusive school environments for people with disabilities. Through a counter-positioning of personal experience and scholarly recommendations, I examine the current landscape of accessibility concerns in two different Ontario secondary schools.

\section{Identifying Barriers}

According to Ainscow (2012), the aim of inclusive school improvement is "to eliminate exclusionary processes from education that are a consequence of attitudes and responses to diversity in race, social class, ethnicity, religion, gender and attainment, as well as with regards to disabilities" (p. 2). "Leaders have a central role in working with their colleagues to foster an inclusive culture within their schools" (p. 18). My initial welcome to the practicum school was enthusiastic and heartfelt, which prompted me to believe that I was entering a very inclusive environment. I was excited and nervous for my initial visit, hoping to leave a good impression. I was able to foresee several accessibility problems, but my first practicum jitters masked the accuracy of how difficult the upcoming weeks of my practicum would be.

In the fall of 2010, my mother held the door open for me as I entered a local secondary school two weeks before my first teaching practicum. I headed immediately to the office to announce my arrival to the secretary. I was politely greeted by the principal who was very enthusiastic to have me as a student teacher in her school. Right away she took me for a tour of 
the building, and then escorted me to the classroom where I would be working. I met my supervising teacher, who was also eager to meet me, and started going over her classes and procedures. Both the principal and teacher treated me kindly and enthusiastically, as if I were no different than any other student teacher. For me, this represented a symbol of respect.

Every day my parents would drive me to school and open the double set of doors for me to enter the building. Electric door openers had been installed two weeks after my first arrival to the school. However, they were routinely disabled at night and not turned on again in the morning until after I was already in the building. It thus became a daily necessity that I needed help maneuvering through the entrance doors.

My practicum was conducted in a small room on the main floor of the school. Three rows of tables, with chairs, consumed most of the space. When class was in session, being able to maneuver down the rows in my wheelchair was an impossible task. Lack of space also hindered any use of the chalkboard located at the front of the room or the use of an overhead projector. These teaching tools were inaccessible for me and I relied on other strategies such as preparing bristol board presentation ahead of time to teach throughout my practicum. The classroom had received a SMART board before my arrival; however, it remained in its box leaning against the chalkboard at the front of the room. The SMART board, taking up space, eventually was moved, but was not set up until weeks after my practicum. Supplies and textbooks were also on shelves or in areas of the room I could not reach. Students and staff were more than accommodating, getting supplies I needed when asked. When I was alone, however, accessing supplies was not possible. I was therefore reliant on others, and sometimes felt frustrated by my lack of independence, which I felt was caused by my own physical limitations.

Washroom facilities also involved the co-operation of others. Because there were no wheelchair accessible cubicles in the female staff or student washrooms, I initially resorted to the closet washroom in the principal and vice-principal's office. This washroom was definitely not a perfect solution. My wheelchair was too large to close the washroom door. However, I was able to close the principal and vice-principal's door entrance to create privacy. This was going to be my personal washroom for the first two weeks of observation before my practicum. At first 
Principals’ Roles and Responsibilities

it seemed to work, but quickly I realized the absurdity of the situation. Because there was no lock on the closet doors, I had to inform the secretary and both administrative leaders when I had to use the facilities. I lived in constant fear that someone would accidently open the closet door, and anticipated the embarrassment of the situation. I also had to interrupt the day-to-day business of the administration and principal's office, such as meetings with parents, important phone calls, or student disciplinary chats, so that I could sneak into my "personal washroom." Although no one ever asked, I imagined those visiting the administration office, such as parents, students, and even teachers, would wonder why on earth the little blonde girl in the wheelchair just went into the closet.

Because there were no elevators in the building, I could not visit the cafeteria or use the computer lab, resource room, or any classrooms located on the second floor. I was restricted to the main floor of the school, and often felt segregated because of my situation. I believed myself to be the problem and not the physical limitations of the school. I never spoke out about my concerns, because being the "new one," I did not want to feel like a bother, especially because of my disability.

A particular incident during my first practicum took place while I was working in the photocopier room prepping for future lessons. The door of the room had to be propped open because it was too heavy for me to open and maneuver. While working, I overheard a conversation between the secretaries, the guidance counselor, and principal, who were having coffee in the office next to me. They were talking about me, their conversation centered on my disability. They spoke of how I had acquired my disability and how I have managed my recovery, with many factual errors in their version of the story. They continued their conversation without knowledge of my presence next door, and even though they spoke in a positive light about my situation, I definitely did not feel good about myself. The stress of being new to the school and learning to cope with my disability was overwhelming. Now knowing that I was somewhat a personal topic of gossip, created additional stress, and caused my professional work to feel even more challenging. 
Principals’ Roles and Responsibilities

My first practicum caused an overwhelming surge of emotions, not only because I was a new student teacher, but also because I had a fairly recently acquired disability, and I often extended the limits of my body and mind. I initially assumed that my first practicum would come with problems, difficulties, and concerns, but I never imagined the alarming difficulty presented by my physical disability. I presented myself as if, made of iron, everything was just fine. However, everything was not fine. I sometimes came home exhausted and in tears of frustration about my physical limitations. I was affected emotionally, physically, and mentally, but finished my practicum with great reports of success and accomplishment, despite the challenges I faced. I never once questioned my ability to teach and have an educational career. I did, however, question what additional challenges my disability would pose, and whether these challenges would jeopardize my decision to stay in the educational field.

Governments across North America since the 1980s, have adopted and legislated practices and policies to move education systems in a more inclusive and integrated direction for those with disabilities (Ainscow, 2005). The Ontario Ministry of Education (2009) calls for "each school to create and support a positive school climate that fosters and promotes equity, inclusive education, and diversity" (p. 11). Under the 2001 Ontarians with Disabilities Act, the Ministry of Education, along with school boards, are required to prepare, update and make public accessibility plans that address the identification, removal and prevention of barriers for people with disabilities. Barriers can take a variety of forms and can consist of physical, attitudinal, technological, systemic, or financial obstacles (Valeo, 2010). In my practicum, various obstacles contributed to my individual experience of physical and technological barriers, while both attitudinal and physical barriers enhanced my sense of isolation, awkwardness, and embarrassment.

\section{Physical Barriers}

It is surprising that, in the year 2012, we are still facing architectural impediments that fail to meet the basic accessible requirements of public buildings, including schools. Such aids as electric door openers and handicap-accessible cubicles in washroom facilities improve a school not only for its educational purposes, but also for community hosted events, drama productions, 
government use (e.g., voting stations), and other occasions when people of the community access the building.

During my first practicum, in addition to the physical barriers I experienced, I also became aware that, due to the inaccessibility of the school, students with disabilities are forced to attend another high school not located in their own neighbourhood. If all publicly funded schools and administration are to facilitate equitable access for all people and equal representation of all minorities (Goddard \& Hart, 2007), does this current practice not violate equitable policy, regulations, legislation and democratic standards? "Educators are ethically responsible for attempting to address all interests and aspirations of diverse communities" (Ornstein \& Hunkins, 2009, p. 223). By marginalizing students and teachers with physical disabilities, are not traditional trends of discrimination, segregation and schools of dominant culture being allowed to thrive in modern communities?

\section{Attitudinal Barriers}

According to Goddard and Hart (2007), avoidance strategies, such as treating everyone the same in order to minimize difference, are commonly used as an attempt to achieve equity and handle differences that leadership and administration are uncertain about handling. At the beginning of my practicum, I was treated equally, as any other "able" individual. As a new disabled student teacher and guest at the school, I initially perceived this treatment as a sign of respect. However, attention to individual needs is crucial for the success of students, especially those who cannot advocate for themselves (Goddard \& Hart, 2007). In my situation as a new student teacher, I did not know what to expect in the classroom or school environment, and could not advocate personally for my basic needs, such as washroom facilities. Attempts to minimize my physical difference from able individuals served as an attitudinal barrier that I did not immediately recognize.

Colleagues talking about me as I worked in the room next door exacerbated my perception of attitudinal barriers. I seemed to be recognized as the new student teacher who carried the burden of being in a wheelchair, and more notably was part of a very small minority. According to Ross and Berger (2009), it is the task of principals to develop a culture of inclusion and promote understanding of the disabilities that exist in their school. When people expressed curiosity about my disability, I believe I should have been informed and included in the 
discussion, perhaps to clarify misconceptions and encourage knowledge building. No such channels of communication existed in my practicum situation. According to Ryan (2006), especially in diverse settings, administrators, teachers, students and parents generally know too little about each other and about inclusive issues. In order to face the challenges associated with inclusion, new knowledge, understanding, and attitudes need to be established. This is best achieved when "all members of the school community have to assume the role of both teacher and learner" (Ryan, 2010, p. 12).

\section{Technological Barriers}

Fineman, Gabriel, and Sims (2010) proposed that technology, machines, and tools help protect us against our natural environment, help us control and profit from its resources, and help make our lives easier. However, technology can became a barrier for many people very easily. For me, technology becomes a barrier when it is inaccessible due to physical barriers, including where it is located and how it is made. Several examples from my practicum experience include PA systems that were too high for me to reach, photocopiers that were too tall for me to use, and computer labs located on inaccessible floors in the building. I generally cannot write on chalk boards due to height; overhead projectors and TVs take up too much room for me to maneuver around in classrooms, and I have yet to work in a classroom that is equipped with a SMART board.

\section{Preventative, Not Reactive Actions toward Disability Issues}

I was in my second practicum and working in what was labeled an accessible school, equipped with electric door openers, an elevator, and private handicapped washrooms with locks. It was third period, just after lunch, and my supervising teacher and I were preparing for fourth period class. We heard a knock at the door where a student was waiting to get our attention. The student had been sent from the main office to deliver a message that we would be having a fire drill near the end of the period. My supervising teacher, who also has a physical impairment, thanked the student and turned to me, saying, "We better get down stairs before the alarm goes off and the elevators stop working!" She began walking slowly, with a pronounced limp. Due to hip problems, she was in constant pain and always used the elevator to get between floors. 
As we headed to the elevator, we were met by others with mobility issues who had also been warned about the impending fire drill. One was a girl on crutches with a broken foot, and the other, a boy in a wheelchair who has a developmental disorder. Accompanying him was his attendant. After we all made it to the main floor and proceeded outside before the fire alarm rang, I asked, "How would we have got downstairs in case of a real fire?" My supervising teacher looked at me and said, "You know what? I'm not sure...I know that that young boy can stand and walk a little, so I believe he is able to take the stairs. But you and I, I'm not sure?" At that moment, the fire alarm sounded and interrupted our conversation. While the students came out of the building and the teachers gathered to chat, I remained dumbfounded, wondering what would happen in case of a real fire. What options did I have to get down two flights of stairs? I also knew there were other students in other areas of the school who were wheelchair bound or had other forms of disabilities. I wondered where they were at this moment. I also wondered why I had not been formally notified about what happens in case of a fire. Is there a procedure for people with disabilities? And do others know about it?

Later I realized that, for the two years I had attended university in a wheelchair, I also had no knowledge of procedures for my evacuation from upper floors or the basement in case of fire or other emergency when the elevators would stop working. To follow up, I later approached a university faculty member, who had no answer. I then brought this issue forward at a university accessibility meeting. The result was that a presentation was held for those attending the next meeting. However, what about others within the institution? Should not all faculties and departments be informed of such potential situations and their consequences?

Valeo (2010) discovered that the more experience and knowledge school leaders have about disability issues, the more informative and involved they become in supporting safe and inclusive environments. Administrators have the responsibility to understand legislations and regulations around disability issues and must supervise all accessibility aspects of the school, including building, budget, and personnel concerns (Goddard \& Hart, 2007; Ontario Human Rights Commission, 2008; Reynolds, 2008; Valeo, 2010). Administrators are responsible for implementing procedures surrounding disability concerns and ensuring that others, including staff and students, are aware of such procedures. The role of administrators also consists of 
modeling correct practices and finding/providing quality resources, both material and personnel, in helping promote disability awareness, safety procedures, and other concerns (Valeo, 2010). These procedures and practices should remain an on-going process of monitoring and adjusting, as well as firmly entrenched in day-to-day activities (Ryan, 2010, p. 17).

Illustrated in my narrative are several concerns that I, a teacher candidate, never considered before. My school colleagues and I did not know the correct safety procedures for evacuating those with disabilities out of an "accessible" school in case of a fire emergency. This to me is both alarming and discomforting. I wholeheartedly believe that all people with disabilities must be formally made aware of and trained in evacuation procedures in buildings where they spend considerable time. In schools, teachers and administrators in charge of students with disabilities should also be formally trained, while all personnel (including custodians and support staff) should be made aware of evacuation procedures for those with disabilities. If evacuation fire drills are a regular procedure, then those drills should include procedures for people who require additional help, as in a real-life situation. These procedures should be implemented as preventative strategies, and not reactive strategies after the fact. Developing inclusive practices in schools "involves social learning processes within a given workplace that influences people's actions and, indeed, the thinking that informs these actions" (Ainscow \& Sandill, 2010, p. 403).

The fire alarm incident brings to account the concept of an act of moral purpose described by Fineman, Gabriel and Sims (2010, pp. 179-195), Goddard and Hart (2007) and Valeo (2010). Moral purpose is defined by Valeo (2010) as "acting with the intention of making a positive difference in the lives of employees, customers, and society as a whole" (p. 8). Moral purpose is the heart and center of effective leadership and, when modeled, benefits entire organizations toward the betterment of all. Irvine, Lupart, Loreman, and McGhie-Richmond (2010) proposed that, when issues such as disability are viewed in a positive pro-active light, and top-down accessibility initiatives are implemented, authentic inclusion is much more successful. When school leaders extend themselves beyond the classroom to meet the needs of diverse students, thereby setting the appropriate ethical direction, educational change can be positively established. I view moral purpose as leadership enacting preventative strategies, taking charge of disability concerns, and monitoring practices and procedures. In the case of emergency safety 
procedures, I strongly believe that administrative leaders should take pro-active preventative strategies to avoid unfortunate incidences that invoke unplanned and responsive actions.

\section{Realities and Challenges Principals Face}

While all educational personnel are responsible for meeting the needs of students with disabilities, much appears to rest on the capabilities of school administrators and their actions (Ross \& Berger, 2009). Administrators' roles in leadership, mediation, and collaboration, crucially influence the success of inclusive school organizations (Goddard \& Hart, 2007; Irvine et al., 2010; Ross \& Berger, 2009; Valeo, 2010). "[S]chool leaders need to attend to three broad types of tasks: fostering new meanings about diversity; promoting inclusive practices within schools: and building connections between schools and communities" (Ainscow \& Sandill, 2010, p. 409). However, according to Irvine et al. (2010), administrative leaders have reported increased stress in response to their "expanded responsibilities, increased demands from the teaching staff, and heightened accountability" (p. 72). Valeo (2010) similarly noted that inclusion, a social movement affecting educational systems since the mid 1970s, has generated considerable pressure from parent groups, educators, and communities. Reynolds (2008) recognized that school districts have failed to

provide effective special education training for general education teachers and administration [which] has fallen short in the need to address this compelling area. The absence of this education sets the stage for feelings of defensiveness, reluctance, and apprehension among school administrators. (p. 18)

There is a large body of information on inclusive leadership; the challenge is "sifting through the reams of material in ways that will help us understand and promote inclusive leadership" (Valeo, 2010, p. 1). Management books contain copious advice, but the advice is often "contradictory, general, and at the end of the day non-actionable" (Valeo, 2010, p. 1). Despite how or why principals are falling short of becoming successful in creating inclusive and safe school environments, Reynolds (2008) recommends these four major points: (1) Get Educated - inquire and understand disabilities and the unique challenges they create, (2) Apply Training - develop an action plan, grow faculty support, promote parent acceptance, and promote understanding by students in the general classroom, (3) Gather Resources - actively seek assistance from local school districts, special education, and federal government, in order to 
continuously generate more knowledge, and (4) Keep the Moral Message Clear - truly welcome suggestions and relationships that will communicate the change in vision for the school. The sharing of knowledge among all levels of school personnel will not only help administrators, and relieve some of the pressure that is often placed on school leaders, but also promote a culture of ethical standards and equity through appropriate accessibility strategies.

\section{Concluding Thoughts}

This paper has given me the opportunity to examine my own personal experiences as a disabled teacher candidate and formulate a better understanding of the requirements and expectations needed to accommodate someone who possesses similar needs. The roles and responsibilities of administrators have directly influenced my experiences in two schools, and reflect a need to seriously investigate accessibility issues for others, as well as myself. According to Ornstein and Hunkins (2009), the "lifeworld of a school refers to the culture of the school with its attendant meanings that hold significance to the key players in that lifeworld - the teachers and the students" (p. 226). Implementing meaningful change to that lifeworld "actually requires the shaping of the school culture, that is, shaping the norms and behaviours extant in the school or school district" (p. 227). "[L] eadership in schools needs to be about deeper moral purpose like social justice..." (Ryan, 2006, p. 1), and school leaders must prepare, update, and make public accessibility plans that address the identification, removal and prevention of barriers for people of any minority group if we are to move forward toward an inclusive society.

Christine Rougoor is a graduate student at Brock University's Faculty of Education and the recipient of the 2011 Board of Trustees Spirit of Brock Medallion. Her research focuses on teachers with mobility issues within the classroom, a close and passionate topic of interest for her. Christine has spoken widely on the topic of living with spinal cord injury.

\section{References}

Ainscow, M. (2005). Developing inclusive education systems: What are the levers for change? Journal of Educational Change, 6(2), 109-124.

Ainscow, M. (2012). Making schools more inclusive; Lessons from international research. Unpublished Manuscript.

Ainscow, M., \& Sandill, A. (2010). Developing inclusive education systems: The role of organisational cultures and leadership. International Journal of Inclusive Education, 14(4), 401-416.

Fineman, S., Gabriel, Y. \& Sims, D. (2010). Organizing and organizations (4 ${ }^{\text {th }}$ ed.). Los 
Angeles, CA: Sage.

Goddard, J. T., \& Hart, A. C. (2007). School leadership and equity: Canadian elements. School Leadership and Management, 27(1), 7-20.

Irvine, A., Lupart, J. L., Loreman, T., \& McGhie-Richmond, D. (2010). Educational leadership to create authentic inclusive schools: The experiences of principals in a Canadian rural school district. Exceptionality Education International, 20(2), 70-88.

Ontario Human Rights Commission. (2008). Guidelines on accessible education. Toronto, ON: Ontario Human Rights Commission.

Ontario Ministry of Education. (2009). Ontario's equity and inclusive education strategy. Toronto, ON: Ontario Ministry of Education.

Ontario Ministry of Education. (2011). Ontario schools, kindergarten to grade 12: Policy and program requirements. Toronto, ON: Ontario Ministry of Education.

Ornstein, A. C., \& Hunkins, F. P. (2009). Curriculum: Foundations, principles, and issues $\left(6^{\text {th }}\right.$ ed.). Toronto, ON: Pearson.

Reynolds, B. H. (2008, November/December). Are principals ready to welcome children with disabilities? Principal, 88(2), 16-19.

Ross, J., \& Berger, M. J. (2009). Equity and leadership: Research-based strategies for school leaders. School Leadership \& Management, 29(5), 463-476.

Ryan, J. (2006). Inclusive leadership and social justice for schools. Leadership and Policy in Schools, 5(1), 3-17.

Statistics Canada. (2009). Advancing the inclusion of people with disabilities. Ottawa, ON: Human Resources and Skills Development Canada.

Valeo, A. (2010) "Be strong, know what you need": A narrative on inclusive leadership. In Education Journal, 16(2). Retrieved from http://ineducation.caarticlebe-strong-knowwhat-you-need-narrative-inclusive-leadership 